\title{
Nursing Diagnoses for the Patient with Werdnig - Hoffman Syndrome in a Pediatric Intensive Care Unit
}

\section{Márcia Gisele Peixoto Kades ${ }^{1}$, Maria Eduarda Silvano de Aquino Freitas $^{2}$, Laurindo Pereira de Souza ${ }^{3 *}$, Rafael Ayres Romanholo ${ }^{4}$ and Cídia Vasconcellos ${ }^{5}$}

${ }^{1}$ Specialist in Higher Education Didactics by FACIMED/Cacoal-Rondônia, Specialist in Oncologic Nursing by FAVENI, Specialist in MBA and Management of Public Institutions by IFRO-Cacoal/Rondônia, Professor at FIMCA Campus Jarú-Rondônia, Brazil

${ }^{2}$ Specialist in Nursing in Advanced Aesthetics and Cosmetology by FACIMED/ Cacoal-Rondonia, Specialist in Nursing in Neonatal and Pediatric ICU by FAVENI, Resident in Hospital/Urgent Care and Trauma, by Hospital de Emergencia de Cacoal-HEURO-Rondônia, Brazil

${ }^{3} \mathrm{PhD}$ Student in Health Sciences at the Institute of Medical Assistance to Public Servants of the State of São Paulo-IAMSPE/SP, Master in Health Sciences by IAMSPE/SP, Coordinator of the Multiprofessional Residency Program in Intensive Care at Hospital Regional de Cacoal (HRC)/Rondônia, Brazil

${ }^{4}$ Post-Doctorate and Professor of the Health Sciences Stricto Sensu Post-Graduation Program at Faculdade Medicina da Universidade de São Paulo-FMUSP and of the Health Sciences Stricto Sensu Post-Graduation Program IAMSPE/São Paulo, Brazil ${ }^{5} \mathrm{PhD}$ in Regional Development and Environment-UNIR-Professor at the Federal Institute of Rondônia - IFRO Campos de Cacoal/RO - Researcher of the Human Motricity Research Group Health and Society (IFRO) Cacoal/Rondônia, Brazil *Corresponding Author: Laurindo Pereira de Souza, PhD Student in Health Sciences at the Institute of Medical Assistance to Public Servants of the State of São Paulo-IAMSPE/SP, Master in Health Sciences by IAMSPE/SP, Coordinator of the Multiprofessional Residency Program in Intensive Care at Hospital Regional de Cacoal (HRC)/Rondônia, Brazil.
Received: February 06, 2021

Published: February 26, 2021

(C) All rights are reserved by Laurindo

Pereira de Souza., et al.

\begin{abstract}
Objective: The objective of this research was to investigate the clinical and epidemiological profile of WHS patients, their diseases and propose the main nursing diagnosis labels.

Methods: This is a retrospective, descriptive, cross-sectional, qualitative and quantitative field survey of 02 children who were admitted to the Pediatric Intensive Care Unit of the Regional Hospital of Cacoal in the period of October from 2015 to June 2016, with a confirmed medical diagnosis of Werdnig-Hoffman Syndrome (WHS).
\end{abstract}

Citation: Laurindo Pereira de Souza., et al. "Nursing Diagnoses for the Patient with Werdnig - Hoffman Syndrome in a Pediatric Intensive Care Unit". Acta Scientific Nutritional Health 5.3 (2021): 69-76. 
Results: A total of 31 nursing diagnoses were elaborated, 19 being common to the two cases, 6 elaborated only to the WHS 1 case, and 6 to the WHS 2 case only.

Final Considerations: It is concluded that children with WHS present care needs in both physical and biological aspects, as well as psychic aspects, especially in the family experience of the disease process. Nursing integrates the multidisciplinary team, and because of the complexity and integrality of its care, it stays with the patient/family for a longer time, and must be trained to recognize their needs, both biologically and psychologically.

Keywords: Werding-Hoffmann Syndrome; Nursing Process; Intensive Care Unit; Nursing Diagnoses

\section{Introduction}

Werdnig- Hoffmann Syndrome (WHS) also known as Spinal Muscular Atrophy (SMA) type 1, is a degenerative neuromuscular disease with autosomal recessive inheritance, characterized by muscle atrophy and weakness [1]. It is a rare disease, with high mortality and initial onset of symptoms in the first two months of life or even intrauther $[2,3]$.

The evolution of WHS is progressive, therefore, it requires several special care, which can park the progress of the disease and prolong the patient's life. The management is based on monitoring and care aimed at improving the quality of life of patients and includes respiratory, nutritional, orthopedic and physiotherapeutic support, so that the child does not have a loss in posture $[4,5]$.

Whereas patients of WHS, are children who require differentiated service, with features ranging from the non - verbalization to the family commitment, this research is justified by the relevant contribution to the professionals who work in pediatric ICU.

In view of the above, the objective was to investigate the clinical and epidemiological profile of patients with WHS and to propose the main nursing diagnostic labels.

\section{Methods}

This is a quali-quantitative field research retrospective, descriptive, case study type, exploratory character and cross-sectional, conducted in medical records of patients who were admitted to the Pediatric Intensive Care Unit(PICU) of the Regional Hospital of Cacoal/Rondonia(Brazil), from October 2015 to June 2016.

The medical records were selected for convenience, after the researchers' finding of the existence of the cases of WHS, in that hospital unit, inciting curiosity and encouraging reading about the theme. As inclusion criteria, medical records of patients who were admitted to the PICU with a confirmed medical diagnosis of WHS were established. Research were excluded from those records with a diagnosis of WHS and progressing to death within 48 hours degenerative diseases number that does not correspond to the ammonium Spinal cord trophic type I and records with illegible handwriting.

The data collection was carried out through a instrument built by researchers and validated by experts with application of the "pilot", containing questions objective and subjective, personal data of patients, family history, past history and history of present illness, with hospitalization dates and procedures, complications and the main medical and nursing procedures.

After data collection, the information obtained was tabulated in Excel $^{\circledR} 2013$ spreadsheet, building a database. Later this information was distributed according to the objectives of each stage of the research.

In order to carry out the research in accordance with Resolution 466/12 of the National Health Council, the Ethics and Research Committee (ERC) of the Faculty of Biomedical Sciences of CacoalFACIMED/Rondonia(Brazil), under CAAE: 67645617.5.0000.5298 and protocol number: 2.088.748, was required for approval.

\section{Results}

The results of the study were presented based on two case studies through medical records of two (02) children who were admitted to the intensive care unit pediatric (PICU) public a Hospital reference on health in the southern region of Rondônia, with diagnosis confirmed doctor of WHS.

The two selected medical records were described as case WHS 1 and case WHS 2, in order to maintain the confidentiality and anonymity of information regarding patients. Sequentially, it was treated, from a male child to another female, both cases had a medical 
diagnosis of the disease confirmed at around 5 months of age, the reason for admission to the PICU was pneumonia, a disease that directly affects the lung parenchyma. And hinders gas exchange, increases respiratory work, which can contribute to tissue hypoxia.

Table 1 shows the variables $d$ the epidemiological profile (age, gender, age at diagnosis, related conditions) and, also outcomes of the cases described in this study.

\begin{tabular}{|l|c|c|}
\hline \multicolumn{1}{|c|}{ Variables } & WHS 1 Case & WHS 2 Case \\
\hline Sex & Male & Female \\
\hline Age n o Diagnosis & Pneumonia & Four months \\
\hline $\begin{array}{l}\text { Reason initial d } \\
\text { hospitalization }\end{array}$ & Bronchopneumonia \\
\hline $\begin{array}{l}\text { Age at PICU admission } \\
\text { at the referred Hospital } \\
\text { Unit }\end{array}$ & $\begin{array}{c}\text { 1 year and } 4 \\
\text { months }\end{array}$ & 1 year and 13 days \\
\hline $\begin{array}{l}\text { Length of stay in the } \\
\text { PICU of the } \\
\text { referred Hospital Unit }\end{array}$ & Death & $\begin{array}{c}\text { Home care hospital } \\
\text { discharge } \\
\text { - Home-Care. }\end{array}$ \\
\hline \begin{tabular}{l} 
Outcome \\
\hline
\end{tabular}
\end{tabular}

Table 1: Distribution of the epidemiological profile of WHS cases admitted to the PICU of Hospital Regional de Cacoal/Rondonia (Brazil).

Source: The authors (2020).

The case WHS 1 , was a male child, initially admitted at 5 months, in a hospital in the state capital, with a medical diagnosis of Pneumonia (PNM), evolved with respiratory worsening without, however,finding radiological worsening,undergoing early tracheostomy.

The Genitors reported delayed neuropsychomotor development, leading the medical team to suggest a hypothesis of neuromuscular disease, elucidated by means of electroneuromyography such as Spinal Muscular Atrophy type I. He was submitted to gastrostomy and other intensive care. Later, at the age of 1 year and 4 months, she was transferred to the PICU of the Regional Hospital of Cacoal.

He presented with significant motor deficit, but with facial responsiveness to stimuli. He presented hemodynamic instability, with episodes of tachycardia, bradycardia, tachypnea, and 03 episodes of reversed cardiopulmonary arrest(CPA). The family mem- bers had difficulty in social relationships with the multidisciplinary intensive care team, and few participants in the treatment, did not allow the team to perform invasive procedures that led the child to feel pain even with painkillers being administered, facts described by the psychology service as a form of denial of the diagnosis of the child's disease.

The case WHS 2 this was child the female, hospitalized at 4 months of age for treatment of bronchopneumonia, who developed septic shock in hospital from the state capital. During hospitalization was observed developmental delay psychomotor, hypotonia mostly of upper and lower limbs and difficulty in swallowing, and examinations carried out complementary that showed Spinal amyotrophy type I (SAT) and Cardiomyopathy Hypertrophic.

Child was submitted to tracheostomy, gastrostomy and admission to the intensive care unit, being transferred in December 2015 to the PICU of the Regional Hospital of Cacoal, aged 1 year and 13 days. The parents of the WHS 2 case were shown to be collaborative with the treatment, discussed information regarding the clinical conditions, including requiring the intensive care team to de- hospitalize the child in order to continue the treatment at home. The child remained in this unit for 195 days. He was discharged from hospital in June 2016, after the family was able to provide HomeCare care by a private health insurance team.

Table 2 presents the main nursing diagnostic labels and their respective domains according to NANDA international, grouped according to the committed basic human needs(BHN) concerning WHS 1 and WHS 2 cases.

\section{Discussion}

According to the Association of Friends of Spinal Muscular Atrophy [7], and the genders are affected proportionally in view of being an inherited and autosomal recessive genetic disease.

Regarding the confirmation of the medical diagnosis, it occurred around 05 months of age in both cases, in agreement with the authors' studies [8], which describes that the clinical manifestations of this syndrome invariably appear around the first six months of life.

Both cases described in this research, had initial diagnoses of respiratory disorders, which contributed to hospitalization in the intensive care unit, corroborating, researchers [9] describe respiratory infections as the main cause of acute respiratory failure, due to the inability of this patient to take deep breaths and coughing 


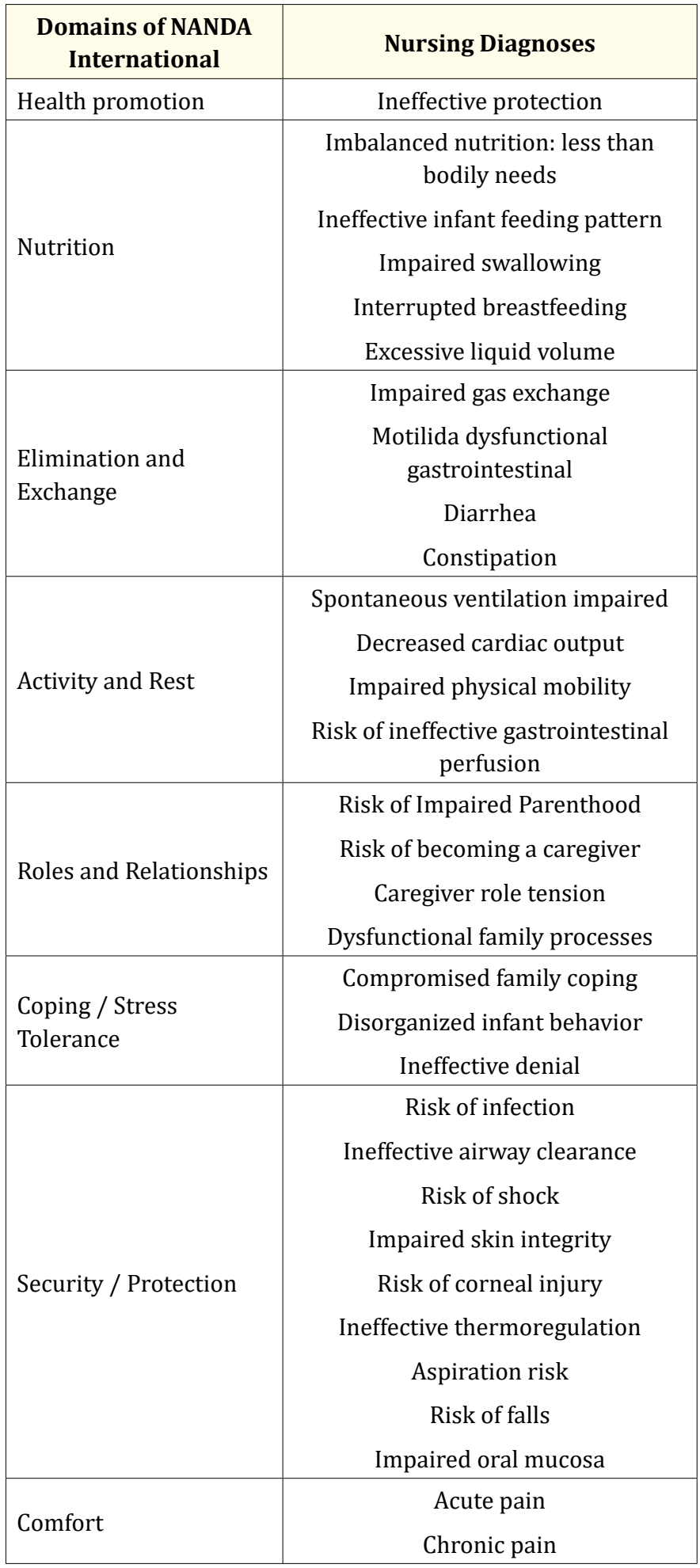

Table 2: Distribution of nursing diagnostic labels and domains concerning the cases WHS 1 and WHS 2 based on BHN at the PICU Cacoal/Rondônia(Brazil).

Source: Herdman; Kamitsuru, 2018 [6]. properly, retaining secretions and developing atelectasis, being considered the cause of death in most cases and hospitalization in ICUs [7].

Regarding ventilatory support, both WHS 1 and WHS 2 cases used a tracheostomy device. In children with type 1 SAT, for ethical reasons, there is no consensus in the literature on the indication of non-invasive ventilatory support, with tracheostomy and mechanical ventilation being less frequently indicated. Generally, the indications for its use are peak cough flow (PCF) less than $160 \mathrm{~L} /$ $\min \left(\right.$ or $2.7 \mathrm{~L} / \mathrm{sec}$ ) and baseline $\mathrm{SatO}_{2}$ less than $95 \%$ due to chronic saliva aspiration [10].

The cases described in the present research, remained for long periods in the PICU, which produces an intense emotional strain for families. During data collection, it was observed that although adopting different strategies, the parents of both cases had difficulties in dealing with their children's diagnosis [11]. Researchers [12] report, that rare diseases have a strong impact on families, generating needs that surpass those associated with the most frequent diseases.

The WHS 1 and WHS 2 cases have similarities to each other, in terms of the compromised human needs. Human needs are understood as states of tension essential to survival and resulting from homeostatic imbalances. They are interrelated and universal. They are common to all humans, however the way they show themselves and how they are solved is what will individualize each being [13]. From the reading of the medical records, the results found were grouped according to the compromised human needs, and subsequently the nursing diagnoses (ND) inherent to each case were elaborated, these were distributed according to the NANDA International minima [6].

Some diagnoses were made for both WHS 1 and WHS 2 cases, according to the following distribution: The diagnosis of "Imbalanced nutrition: less than body needs" defined as insufficient nutrient intake to meet metabolic needs, and the diagnosis "Impaired swallowing" defined as the abnormal functioning of the swallowing mechanism associated with deficits in oral, pharyngeal or esophageal structure or function are directly related [6]. Other researchers claim [8] that given the inability to swallow, and to feed these children, they commonly develop malnutrition.

The diagnosis of "Interrupted breastfeeding" defined as the break in the continuity of milk supply to an infant or young child, directly from the breasts is linked to the diagnosis "Ineffective in- 
fant feeding pattern" defined as the impaired ability of an infant to suck or to coordinate sucking [6], which according to researchers [14], is explained by the symmetrical muscular weakness, areflexia, and fasciculations of the tongue, making it impossible to suck child.

The diagnoses "Impaired gas exchange", defined as the excess or deficit in oxygenation and/or elimination of carbon dioxide in the alveolocapillary membrane, characterizing the difficulty in breathing, associated with the abundance of pulmonary mucus [6], researches [15] reveal that clear unique pathology, is directly related to the diagnosis "impaired spontaneous ventilation" is defined as decreased energy reserve, resulting in failure to maintain independent breathing and suitable for sustaining life, and also the diagnosis "ineffective $d$ the airways" described as the inability to clear secretions or obstructions from the respiratory tract to keep the airways clear [6]. Ferreira and Mejia [8] the tribe in early mortality in patients with this syndrome to repeated manifestations of acute respiratory disorders, due to fatigue or failure of the muscles responsible for breathing.

"Decreased cardiac output" defined by insufficient amount of blood pumped by the heart to meet the body's metabolic demands. The child affected by this disease will have weakness in the muscles, which can cause death by suffocation since the heart, over the course of the disease, will not have the strength to beat $[6,15]$.

The diagnosis of "Impaired physical mobility" is the limitation of independent and voluntary physical movement of the body at one or more extremities, characteristic of WHS since symptoms of hypotonia, areflexia, paralysis or paresis are common, amyotrophies compromising movements [6,8].

"Risk of falls" defined as the vulnerability to increased susceptibility to falls, which can cause physical damage, and compromise health is explained by NANDA International as a risk factor for age $<2$ years and related to impaired physical mobility [6].

"Risk of impaired paternity or maternity" is the vulnerability to the primary caregiver's inability to create, maintain or recover an environment that promotes the child's optimal growth and development and that can compromise his well-being [6].

According to researchers [16], the risks of rejection of care are associated with difficulties during the adaptation phase to the new reality of living with a person with SAT, and the extra demands that this means, that is, overload, misinformation, feelings of helplessness and guilt, and even the need for coping.
"Dysfunctional family processes" defined by the psychosocial, spiritual and physiological functions of the family unit are chronically disorganized, leading to conflict, denial of problems, resistance to changes, ineffective problem solving and the series of self-perpetuating crises. It was found that care management, even when the family caregiver is supported by other people, is a reason for stress and overload $[6,16]$.

"Compromised family coping" is defined when a fundamental person, usually supportive, offers insufficient, ineffective or compromised support, comfort, assistance or encouragement. Studies reveal that the family is weakened by the child's illness and becomes vulnerable to coping with situations $[6,17]$.

"Disorganized infant behavior" are physiological and neurobehavioral responses disintegrated from a link to environmental stimuli6. It is explained by Montalto and Conz [18] as the risk of alteration in the integration and modulation of the systems of physiological and behavioral functioning.

"Risk of infection" is the vulnerability to invasion and multiplication of pathogenic organisms, which can compromise health. Although both cases described have presented events of this type, the risk diagnosis was made, given the long stay and procedures involved in treatment, associated with the chronic disease [6].

"Shock risk" is the vulnerability to inadequate blood flow to the tissues of the body that can lead to life-threatening cellular dysfunction6. Explained by Pereira., et al. [19], as a result of respiratory complications, common to patients with neuromuscular disease, due to the involvement of the ventilatory muscles and pharynx, with consequent cardiac complications that include from arrhythmias, hyperkalemia to cardiac arrest.

"Impaired skin integrity" is the altered epidermis and/or dermis, related by NANDA International to factors such as mechanical factor, physical immobility, impaired circulation, changes in metabolism. Both cases WHS had skin involvement [6].

"Suction risk" who according to the International NANDA and vulnerability to input gastrointestinal secretions, oropharyngeal, solid or liquid secretions in various tracheobronchial [6], described by Vieira [20], as a result of difficulty in breathing and swallowing.

"Dysfunctional gastrointestinal motility", defined as increased, decreased, ineffective or absent peristaltic activity in the gastrointestinal system [6]. Guerra [21], explains that the greatest stimu- 
lus for his movements is food. The autonomic nervous system and hormonal and emotional influences modulate the activities of the digestive tract through reflexes that control secretions, peristalsis, mixing contractions, local inhibitory effects, gastrocolic reflex, enterogastric reflex, colonoileal reflex, reflex defecation and central mechanism reflexes, and with changes in eating patterns, motility dysfunction will consequently occur.

Some nursing diagnoses were elaborated only for the WHS 1 case as: "Diarrhea", which is defined by Nanda International [6], the elimination of loose and unformed feces. For Guerra [21], it is related to the pattern of gastrointestinal motility, nutritional and therapeutic factors.

"Excessive fluid volume" is defined by increased retention isotonic liquids, defined by Nanda International as the result of a compromised regulatory mechanism [6].

"Risk of corneal injury" is the vulnerability to infection or inflammatory injury to the corneal tissue. Critically ill patients are at increased risk for corneal injury, since the mechanisms responsible for lubrication and eye protection may be compromised $[6,22]$.

"Acute pain" is the unpleasant sensory and emotional experience associated with actual or potential tissue injury, or described in terms of such injury; beginning sudden or slow, slight to severe intensity with $t$ anticipated or predicted coin [6]. What which meets with the records concerning the WHS 1 if it had episodes of pain during the procedure.

"Tension of the role of caregiver" is the difficulty to play the role of caregiver for the family/significant people. It is common for the family caregiver of a person with Spinal Muscular Atrophy (SMA) to dedicate himself exhaustively to his relative, as it is a severe pathology that leads to several types of dependence and early death $[6,16]$.

"Ineffective denial" is the conscious or unconscious attempt to deny the knowledge or the meaning of an event to reduce anxiety/ fear, which leads to health impairment $[6,16]$, describes to caregivers health, social monitoring of instrumentalization and psychological empowerment, thereby minimizing the risks of rejection of care.

Some nursing diagnoses were made only for the WHS 2 case: "Constipation" defined as the decrease in the normal frequency of bowel movements, accompanied by the difficult or incomplete elimination of feces and/or elimination of excessively hard and dry feces [6] according to this research [21] is related to the pattern of gastrointestinal motility, as a result of several nutritional and therapeutic factors involved in the treatment.

"Risk of ineffective gastrointestinal perfusion" is defined as vulnerability to reduced gastrointestinal circulation that can compromise health, related to the gastrointestinal motility pattern $[6,21]$.

"Ineffective thermoregulation" is the temperature fluctuation between hypothermia and hyperthermia. Related according to NANDA International to the condition of the disease, and regulatory factors [6].

"Impaired oral mucosa" is defined as injury to the lips, soft tissues, oral cavity and/or oropharynx related according to NANDA International to the treatment regime, and inadequate oral hygiene [6].

"Chronic pain" is the unpleasant sensory and emotional experience associated with actual or potential tissue injury, or described in terms of such injury; sudden or slow onset, of any intensity from mild to intense, constant or recurrent, without anticipated or predictable termination and lasting more than three months, related according to Nanda International to chronic musculoskeletal condition [6].

"Risk of tension in the role of caregiver" is the vulnerability to the difficulty in playing the role of caregiver. Many demands of families are not answered of the team, especially the need to communication $[6,17]$.

It is noteworthy that in the care plan of children with rare disease, it is essential to consider family aspects, since this condition directly affects family members, for this purpose, NDs were developed that understand the physical-biological and also psycho-effective needs of patients with WHS.

The WHS 1 case after 231 days of admission to the PICU aged 1 year, 11 months and 29 days, died. The death declaration (DD) was described as the cause of death: cardiac arrhythmia, hydroelectrolytic disorder, cardiac dysfunction and spinal amyotrophy type 1. Patients with neuromuscular diseases often have an abnormal response to the use of neuromuscular blockers and anticholinesterases. There may be cardiovascular complications that include decompensations, malignant arrhythmias and increased serum 
potassium concentration after the use of succinylcholine, with consequent cardiac arrest [19].

The WHS 2 case resulted in de hospitalization. For scholars [20], hospitalization offers important advantages for the child, because in addition to lower infection rates, better quality of life, it also provides social stimulation favoring the child's development.

The feasibility of leaving the hospital does not depend only on the stabilization of the clinical condition. Families need to adapt to the child's conditions. The house needs to fulfill some criteria, varying according to the type of device to be used by the child and the type of assistance he will receive [23].

\section{Study Limitations}

The limitations of the study were related to the search for retrospective documentary data, and there is not always a complete record of all information, it is possible to highlight another limitation concerning the scarcity of recent studies that addressed nursing diagnoses and interventions related to this syndrome or other syndromes with impairment of identical basic human needs in which the researchers could make similarity.

\section{Study Contributions}

The research brings relevant contributions that, from this study, nurses can take another look at nursing diagnoses and their interventions, thus being able to better implement the systematization of more assertive nursing care, in addition to being a case study, it is expected that other researchers may be awakened to research and develop other research with a larger sample.

\section{Conclusion}

According to the results obtained, the child with WHS presents needs of care both in physical-biological and psychic aspects, mainly in what it understands the familiar experience of the illness process. The nursing integrates the multidisciplinary team, and due to the complexity and integrality of its assistance, remains for more time with the patient/family, and must be trained to recognize the needs of these, both biologically and psychically.

From the analysis of the results found, 31 nursing diagnoses and nursing interventions were elaborated according to the needs of each case. It was verified that there was little divergence of the necessary cares, being the majority of these, common to both cases. The study is relevant, because it contributes to expand the knowledge about WHS carriers, their needs and the multi and interdisciplinary approach.
Throughout the development of this study, related questions were identified that would allow the development of other studies to broaden the understanding of WSH, and multidisciplinary behaviors involved in the treatment of the pathology, and also the behavioral responses of family members of the child with rare disease. Another study suggestion refers to the WHS 2 case, which in the diagnostic investigation was elucidated as a carrier of hypertrophic myocardiopathy, suggesting a study on the correlation of neuromuscular diseases and this diagnosis.

\section{Authors' Contribution}

Márcia Gisele Peixoto Kades and Maria Eduarda Silvano de Aquino Freitas participated in the realignment of the main idea of the study their initial conceptions and design of the study, as well as the organization of data and interpretation.

Laurindo Pereira de Souza, Rafael Ayres Romanholo and Cídia Vasconcellos, participated in the reorganization of the data for discussion, all writing, critical analysis and final release for publication.

\section{Funding}

We declare that there is no funding through a development agency or any other type of funding.

\section{Conflicts of Interest}

There is no conflict of interest on the part of any of the authors.

\section{Bibliography}

1. De Lima MB., et al. "Performance of physiotherapy in WerdnigHoffmann's disease: Case report". Reviews in the Neurosciences 18.1 (2010): 50-54.

2. Nóbrega AMP., et al. "Diagnostic Investigation in Werdnig-Hoffmann Syndrome”. Revista Brasileira de Ciências da Saúde 11.3 (2009): 297-304.

3. Nunes RG., et al. "Síndrome of Werdnig -Hoffman - case report" 11.2 (2011): 10-14.

4. Kades MGP., et al. "Síndrome of Werdnig -Hoffman: pathological aspects and nursing knowledge". São Paulo Rev Recien 7.20 (2017): 40-47.

5. Baioni MTC and Ambiel CR. "Spinal muscular atrophy: Diagnosis, treatment and future prospects". The Journal of Pediatrics 86.4 (2010): 261-270. 
6. Herdman T Heather and Kamitsuru Shigemi. "NANDA nursing diagnoses: definitions and classification 2018-2020” (2018).

7. Association The migos of the trophic Muscular and spinhal ATMS. Spinal Muscular Atrophy. Rio de Janeiro (2018).

8. Ferreira NMD and Meija DPM. "Werdnig-Hoffman syndrome, a case report. 2013". Post-graduation in Physiotherapy at Ter Intensiva-Faculdade Ávila (2013).

9. Fonseca MTM., et al. "Respiratory approach of patients with neuromuscular diseases". Rev Med Minas Gerais 18 (2008): 17 26.

10. Simonds A. "Ethical aspects of home long term ventilation in children with neuromuscular disease". Paediatric Respiratory Reviews 6 (2005): 209-214.

11. Lima EC. "Being a family living with a child dependent on mechanical ventilation: an approach to nursing care". (Master's Dissertation). UFRGS - Federal University of Rio Grande do sul (2004).

12. Luz G dos S., et al. "Priority needs mentioned by the families of people with rare diseases". Texto and Contexto Enfermagem 25.4 (2016): 1-9.

13. Horta WDA. vegetable garden. Nursing: theory, concepts, principles and process". Revista da Escola de Enfermagem da USP 8.1 (1974): 7-15.

14. Resende MAC DE., et al. "Total venous anesthesia (TVA) in an infant with Werdnig-Hoffmann disease: case report". Revista Brasileira de Anestesiologia 60.2 (2010): 170-175.

15. Silva CCP., et al. "An account of experience in pediatric ICU: case of m". VIII EPCC - Int Scientific Meeting Cesumar Ed CESUMAR Mar - Paraná-Brazil (2013).

16. Moura CVA., et al. "Social support network for the family caregiver of a person with spinal muscular atrophy I and II". Rev Bras in Health Promotion RBPS 23.2 (2010): 126-135.

17. Côa TF and Mandetta PMA. "The experience of vulnerability of the family of the child hospitalized in a Pediatric Intensive Care Unit". Revista da Escola de Enfermagem 45.4 (2011): 825-832.

18. Montalto PS and Conz CA. "Proposal for a plan for immediate care of nurses to newborns with gastroschisis, based on NANDA / NIC". Pediatric Mod 7.48 (2012).
19. Pereira SM., et al. "Neuromuscular diseases and neuromuscular-blocking drugs". Revista Médica de Minas Gerais 26.1 (2016): 52-59.

20. Vieira LMN., et al. "The impact of home care on the evolution of Werdnig-Hoffmann's syndrome: case report" 22.4 (2012): 458-460.

21. Guerra SNPR. "Irritable bowel syndrome". The Journal of Pediatrics 76.2 (2000): 157-164.

22. Werli-Alvarenga A. "Effect of nursing interventions on the prevention of corneal injury: randomized clinical trial" (2014): 143-143.

23. Castro BSM. "Knowing and recognizing their homes: De-hospitalization of children with long-term illnesses. Dissertation (Master of Science) - Oswaldo Cruz Foundation, National Institute of Health Rio de Janeiro (2017).

\section{Assets from publication with us}

- Prompt Acknowledgement after receiving the article

- Thorough Double blinded peer review

- Rapid Publication

- Issue of Publication Certificate

- High visibility of your Published work

Website: www.actascientific.com/

Submit Article: www.actascientific.com/submission.php

Email us: editor@actascientific.com

Contact us: +919182824667 